\title{
VIDAS REVISITADAS: A RECONSTRUÇÃO DO PASSADO DE IDOSOS EM PROGRAMAS GERONTOLÓGICOS*
}

Repensar o passado, considerando um indivíduo como sujeito, é parte fundamental da construção da dimensão simbólica do processo social, nas sociedades modernas, propiciando referenciais para as formas de estar no mundo. Os eixos identitários do sujeito moderno estão, em grande medida, conectados a uma visão de suas trajetórias. Mas há, como sabemos, modos muito distintos de realizar este movimento de revisitar o passado, reconstruindo-o seletivamente e ordenando-o. Encadeia-se o acontecido e o não-acontecido, dando, retrospectivamente, sentido e direção às trajetórias. ${ }^{\mathrm{I}}$ Nesse processo de reconstrução, determinados eventos e situações assumem novos significados, enquanto outros são relegados ao esquecimento. Tais operações complexas são emolduradas pelas específicas formas sociais de conceber o tempo e produzem uma memória enquadrada pelas categorias ordenadoras da visão de mundo, iluminando as perspectivas possíveis e estabelecendo uma ampla zona de escuridão. Processo contínuo, feito e refeito em momentos determinados, em sociedades nas quais a forma hegemônica de construção da pessoa pressupõe a construção de sua especificidade qua indivíduo, ${ }^{2}$ situada em termos de seus atributos e nas peculiaridades de sua trajetória, atua, em geral, de modo difuso, dependente de determinadas situações e demandas para se cristalizar como narrativa.

Nas Ciências Sociais provocamos esta reflexão utilizando a técnica de pesquisa amplamente denominada como história de vida, um tipo particular de entrevista centrado na trajetória do sujeito investigado, ${ }^{3}$ através da qual são 
produzidos dados para as mais diversas investigações. Como técnica de pesquisa social, nos anos recentes, sua utilização foi ampliada e suas possibilidades e limitações metodológicas colocadas sob o crivo dos cientistas sociais e historiadores, devido, em parte, à crescente importância assumida pela chamada história oral (ver, por exemplo, Debert, I986). Sua utilização, contudo, não se restringe aos processos de investigação nas ciências humanas: a produção de histórias de vida é utilizada também como instrumento de intervenção por agências de diversos tipos que se propõem não apenas a repensar o passado, mas a reconstruí-lo dentro de certos parâmetros.

Trato, aqui, do processo de reconstrução do passado de idosos engajados em projetos gerontológicos, utilizando material empírico produzido em pesquisas que coordeno. ${ }^{4}$ Considero fundamental acentuar que, da perspectiva em que me coloco, cada uma das narrativas que chamamos de história de vida constitui-se na produção de um texto que "é, de fato, não a pessoa, mas uma versão do self construída por um sujeito” (ver Behar, I995: I5I), mais especificamente dentro de determinados contextos sociais, inclusive os de pesquisa, nos quais deve-se considerar como fundamental a relação entre o pesquisador e o pesquisado, e os de intervenção, nos quais a relação entre os agentes interventores e a clientela não pode deixar de ser considerada. Enfatizo, portanto, o viés interpretativo e situado das histórias de vida como produto específico de um momento numa trajetória de vida.

As histórias de vida de que trato aqui são narrativas privilegiadas porque produzidas em contextos em que parte da intervenção se exerce, justamente, visando a reconstrução da experiência e da memória dos sujeitos engajados, buscando reinterpretá-las a partir de categorias de entendimento das quais, em princípio, eles não se apropriavam anteriormente à sua adesão a tais agências. Sob tal ponto de vista, permitem que sejam examinadas algumas das tensões resultantes do encontro entre referenciais simbólicos muito distintos. Este artigo, portanto, tem dois objetivos principais: o primeiro, de ordem teórico-metodológica, visa acentuar a dimensão interpretativa e situada destas narrativas, explorando a forma como algumas categorias interpretativas ordenam a produção das histórias de vida em agências gerontológicas; o segundo é contribuir para uma discussão mais ampla sobre as formas de relacionamento entre culturas diversas em sociedades complexas, com a reflexão acerca dos resultados de uma pesquisa numa instituição intermediária (ver Velho \& Kuschnir, I996; Berger \& Luckmann, I997), ou seja, numa instituição que procura fazer a mediação entre indivíduos determinados (sua clientela específica) e a visão professada institucionalmente da sociedade, operando num contexto intercultural.

Esta questão repercute um dos maiores desafios que a antropologia enfrentou, logo após a árdua elaboração de um dos seus mais caros pressupostos: a afirmação da diversidade e do relativismo cultural, ou seja, a integração das culturas e/ou sociedades em seus próprios termos. Se este pressuposto rendeu 
alguns dos mais relevantes registros empíricos dessa disciplina, com importantes implicações teórico-metodológicas, rapidamente levou também à constatação de que, se muito era possível aprender com tais modelos "fechados", seu objeto, contudo, estava mais além. Situava-se, antes de mais nada, na busca da compreensão da criação e recriação de diferenças em contextos plurais, enfocando as interfaces e inter-relações das concepções distintas imersas num evidente jogo de poder. Sob tal ponto de vista, as "diferenças", ainda que no centro da reflexão, não são absolutizadas ou substantivadas, redimensionando-se por sua compreensão em múltiplas dimensões que incorporam, como problemática teórica, as complexas relações entre perspectivas distintas.

$\mathrm{Na}$ modernidade avançada este desafio se potencializa, exatamente na mesma proporção em que a comunicação entre as distintas configurações socioculturais se amplia, pela aceleração e popularização dos inúmeros meios disponíveis. A "espetacularização" do mundo, ${ }^{5}$ característica da contemporaneidade, envolve, simultaneamente, uma enorme divulgação das possíveis diferenças e da alteridade e uma série de efeitos relativos à parcialidade com que tais imagens planetárias são divulgadas pela mídia. Efeitos simultâneos e paradoxais de homogeneização e de recriação de diferenças são verificados, ${ }^{6}$ repercutindo nos processos de subjetivação, através da produção de novas identidades e de novos sujeitos, 7 que devem ser buscados, agora mais do que nunca, nos confrontos e interstícios dos sistemas simbólicos de referência.

É neste contexto que devem ser situadas as inúmeras agências gerontológicas que se espalham por boa parte do mundo. A visibilidade adquirida pela "velhice" no mundo atual, particularmente nas duas últimas décadas do século $\mathrm{XX}$, é uma destas reverberações que atravessam fronteiras. Mas, mais do que isto, o processo que os cientistas sociais têm chamado de "construção social da velhice" (ver Debert, I999a; I999b) pode ser compreendido como um dos desdobramentos tardios da regulação e normalização características da "sociedade disciplinar" (ver Foucault, por exemplo, I977; I995), operando persistentemente o deslocamento dos centros de poder, ${ }^{8}$ e tecendo os fios de uma extensa e densa rede que esquadrinha corpos e mentes, produzindo sujeitos, objetos e instituições que os administram. Os programas gerontológicos que proliferaram em várias partes do mundo e, no Brasil, nas duas últimas décadas, são objetivações deste processo, estabelecendo-se como espaços privilegiados para a criação e recriação de novos significados para a velhice, mas é preciso não esquecer que são, também, espaços de confronto de perspectivas. Produziu-se, nestes últimos anos, um "sentimento da velhice" comparável à produção de um "sentimento da infância" na era moderna, como nos demonstrou Philippe Ariés (Ariés, I978).

Esta nova sensibilidade com relação à velhice objetiva-se em grande aparato institucional que incorpora uma série de técnicas, já consagradas em outros campos, para a divulgação e inculcação dos modelos produzidos sobre 
esta etapa da vida. Uma das mais importantes estratégias dos programas de intervenção gerontológica analisados é, justamente, promover uma intensa revisitação da memória individual, utilizando várias técnicas oriundas da psicanálise, da psicologia, da história, da literatura, da sociologia e de diversos outros campos disciplinares. A reconstrução das histórias de vida pelos sujeitos é considerada como um dos mais eficazes instrumentos para a reconstrução de si. Esta operação, entretanto, não se exerce num vácuo de significados. Ao contrário, confronta-se com significados profundamente sedimentados, ${ }^{9}$ gerando uma série de reinterpretações operadas pelos idosos, clientes destas agências. Tais reinterpretações são objetivações novas da relação entre perspectivas que se baseiam em princípios simbólicos distintos.

\section{O PROCESSO DE RECONSTRUÇÃo dO PASSADO EM AGÊNCIAS GERONTOLÓGICAS}

Sob tal perspectiva, é mister considerar a produção narrativa que o sujeito faz de sua trajetória de vida para um pesquisador - sua "história de vida" num dado momento - como parte de um processo social mais amplo. Requer, portanto, a utilização simultânea de outras técnicas de construção de dados que permitam situá-la e compreendê-la, inclusive nos seus impasses. ${ }^{\text {ro }}$ Tal perspectiva analítica propicia uma inquirição mais produtiva destas narrativas cristalizadoras e concentradoras dos significados que referenciam a vida das pessoas, evitando considerá-las como autocontidas e autoexplicativas. As histórias de vida, desse modo, como parte de uma pesquisa mais ampla, podem ser compreendidas no que têm de mais fundamental: como loci de produção e reprodução de sentido, sempre em processo de mudança.

Embora a reconstrução das histórias de vida seja um processo bastante difuso, que ocorre no interior de uma série de instituições nas quais vivem as pessoas, há, entretanto, determinadas instituições na sociedade moderna que, tal como as que aqui estão em foco, atuam diretamente sobre a reformulação da pessoa. Operam segundo alguns modelos do sujeito, nem sempre muito explícitos, cuja realização, em geral, requer uma reinterpretação do passado individual. Desdobramentos do grande aparato da sociedade disciplinar de que nos fala Foucault (ver, por exemplo, Foucault, I977), tais instituições esquadrinham minuciosamente a experiência e a memória do sujeito a que se destinam, lançando luz sobre alguns episódios, situações e atributos, enviando outros ao esquecimento, e, principalmente, fornecendo novas interpretações para o passado individual mais ajustadas ao modelo proposto de "reerguimento" ou "reformulação" da trajetória de vida.

Há uma série de agências deste tipo nas sociedades modernas, instituições intermediárias que atuam revisitando e reinterpretando a experiência dos sujeitos. Os grupos de ajuda mútua, no modelo dos Alcoólicos Anônimos ${ }^{\text {II }}$ ou dos 
Narcóticos Anônimos, são exemplos significativos deste trabalho sobre a experiência individual, utilizando a reinterpretação das histórias de vida como meio e fim de todo o processo. Do mesmo modo, as inúmeras microagências que têm sido, nas últimas décadas, criadas sob a égide da gerontologia têm, como uma de suas propostas fundamentais, a recriação do sujeito idoso, dando surgimento a uma "nova velhice" a partir de um modelo em que as ideias-valores de participação e atividade ${ }^{12}$ são fundamentais. Contra o pano de fundo do diagnóstico de uma velhice abandonada, dessassistida e inativa, tais agências propõem uma completa reavaliação dos limites e possibilidades cognitivos, afetivos e sociais do sujeito idoso. ${ }^{13}$ Atuam, simultaneamente, na tentativa de desconstrução de significados que supõem sedimentados sobre a velhice e na construção de novos significados, utilizando uma série de técnicas, entre elas as que são privilegiadas nos grupos de ajuda mútua. A vulgarização da expressão terceira idade, originária do campo acadêmico e amplamente presente na mídia, ${ }^{\mathrm{I} 4}$ é um dos mais significativos exemplos desta desconstrução/construção, pois sintetiza a rejeição dos valores e significados que se supõe estarem associados à ideia de velhice, buscando acentuar novos valores e possibilidades que abrem um extenso campo de atividades e participação para os idosos.

É necessário acentuar, entretanto, uma diferença importante entre as agências gerontológicas e outros grupos de ajuda mútua muito difundidos na sociedade moderna. Trata-se do fato de que, ao contrário dos grupos de ajuda mútua em que a intervenção profissional é esporádica ou menos explícita, nas agências gerontológicas é fundamental a intervenção cotidiana de diversos especialistas, que orientam, administram e gerenciam o processo. Se, nos dois tipos de instituição, é intenso o trabalho sobre a memória individual, dando continuamente surgimento a novos marcos que a recortam, a intervenção de especialistas na produção da reinterpretação coletiva de experiências individuais nas microagências gerontológicas coloca também em cena uma distinção entre seus usuários e os especialistas que administram todo o processo. A intervenção, neste caso, assume mais nitidamente um aspecto pedagógico.

Os resultados das etnografias que estão sendo realizadas no projeto que coordeno acerca da forma como os idosos vivenciam sua inserção em duas agências gerontológicas distintas criadas na Universidade Federal Fluminense (UFF) ${ }^{\text {I5 }}$ demonstram a importância desta dimensão pedagógica. Estas agências contam com especialistas legitimados pela mais importante associação brasileira neste campo, a Sociedade Brasileira de Geriatria e Gerontologia (SBGG), legitimando-se também como projeção do saber acadêmico através de sua inserção, inclusive em termos de espaço físico, numa universidade federal.

Situadas no eixo classificatório das categorizações etárias, tais agências pretendem disponibilizar para um público determinado um conjunto desigual de saberes acadêmicos - da medicina, da fisioterapia, da psicologia, do serviço social, da sociologia etc. -, congregando-os todos em um campo multidiscipli- 
nar denominado gerontologia, que se propõe a operar a transformação das formas possíveis de atuação dos indivíduos idosos. Para isso, recriam a velhice, intervindo na produção de um marco etário significativo, este característico da modernidade tardia. ${ }^{16} \mathrm{~A}$ naturalização deste recorte encontra sua justificativa mais frequente nas alterações da estrutura demográfica das populações de alguns países, em que o prolongamento da expectativa de vida, associado a outros fenômenos demográficos, tem resultado em uma mudança sensível na estrutura etária da população, com índices crescentes de envelhecimento. Tais diagnósticos, apoiados em estatísticas consideradas incontestáveis, são a linguagem primeira através da qual é operada uma reificação da velhice, bem como sua autonomização como objeto de reflexão e intervenção (ver Debert, I999a; I999b), tanto em termos do discurso acadêmico quanto em termos de vulgarização. Assiste-se, em decorrência, a um intenso processo em que um marco etário, algumas vezes com uma rígida demarcação cronológica (6o ou 65 anos), é tomado como a passagem para uma etapa determinada do ciclo de vida, pensado como universalmente presente. A consideração privilegiada da acumulação de tempo cronológico na produção dos marcos etários, em detrimento de outros princípios classificatórios amplamente utilizados em outras culturas, finda por produzir, simultaneamente, a naturalização da velhice. Sob tal perspectiva, embora as diferenças sociais e culturais sejam consideradas, ${ }^{17}$ elas tendem a ser acrescentadas como variantes de um fenômeno único, da ordem do biológico, portanto objetivado como parte do ciclo vital humano que se atinge através da acumulação de tempo de vida.

A naturalização da velhice como fenômeno biológico inelutável, cria, ao mesmo tempo, um amplo conjunto de especialistas para gerenciar esta etapa da vida, necessariamente com formação acadêmica, abrigados sob as disciplinas da geriatria, especialidade exclusivamente médica, e da gerontologia, especialidade aberta a todos os profissionais graduados. ${ }^{18}$

As duas agências investigadas partilham, conforme se pode depreender de uma literatura que já se acumula, as características mais amplas dos processos de intervenção gerontólogicos, destacando-se a atuação dos especialistas como construtores de uma visão de velhice ativa e participativa ou, como referem frequentemente, de uma velhice bem-sucedida. As especificidades destas agências, por outro lado, situam-se em focos e ênfases que podem, seguramente, ser relacionados às disciplinas acadêmicas hegemônicas em sua formulação.

O primeiro programa analisado desenvolve-se junto à Escola de Serviço Social, mas mantém alguma autonomia em relação à sua estrutura institucional, sem quaisquer limitações no recrutamento de sua clientela. Conta com profissionais diversos ligados à universidade, mas, neste caso, são, em sua maioria, assistentes sociais. A agência, inclusive, funciona também como campo de estágio para os alunos de serviço social da universidade. Seu foco básico 
é a construção da cidadania do idoso, investindo num amplo programa pedagógico centrado no incentivo à conquista de direitos políticos e sociais. ${ }^{19} \mathrm{Em}$ bora incorporando uma série de atividades comuns a todos os programas gerontológicos que visam, por exemplo, a promoção de determinados cuidados com a saúde, é a participação sociopolítica dos idosos o objetivo principal. Este programa se realiza num espaço especialmente destinado a ele, num dos campi da UFF, espaço no qual têm lugar as diversas atividades através das quais se operacionaliza (oficina de memória, oficina de texto, terapia de grupo, dança sênior, ginástica sênior, palestras, festas etc.).

O outro programa investigado tem seus objetivos mais centrados nas questões referentes à saúde do idoso. Isto porque foi criado a partir da clínica geriátrica do Hospital Universitário Antonio Pedro, crescendo e ampliando-se nos últimos anos. Desenvolve-se através de atividades semelhantes ao primeiro, mas, por estar associado a um projeto mais amplo de um setor da Escola de Medicina que envolve, além disso, práticas ambulatoriais, cursos de extensão e especialização em geriatria e gerontologia, recruta prioritariamente sua clientela nos idosos que buscam as clínicas do Hospital Universitário, contando também com um número maior de especialistas ligados à área médica. Também funciona como campo de estágio, neste caso, principalmente para estudantes da área biomédica. Neste programa, o modelo do idoso ativo e participativo que orienta as agências gerontológicas realiza-se, principalmente, através de uma série de práticas que visam a promoção da saúde e os cuidados com o corpo embora, evidentemente, incorporando também outras dimensões (ver Bauer, 2000).

Há, portanto, diferenças de ênfase entre os dois programas, mas, como venho acentuando, é possível considerar tais diferenças como variantes no interior das objetivações desta nova sensibilidade em relação à velhice. De fato, os dois programas partilham a concepção da "velhice saudável", que orienta amplamente suas atividades. Uma das vias principais para a consecução destes objetivos é um intenso trabalho que se realiza sobre a memória de cada um, socializando determinadas experiências selecionadas e produzindo reinterpretações sobre o passado individual. Ou seja, uma das técnicas com as quais ambos trabalham é o gerenciamento coletivo das interpretações sobre o passado individual. Nos dois casos, há também alguma especificidade na forma pela qual este encontro entre diferentes concepções simbólicas - as que são trazidas pelos idosos e o modelo de velhice surgido na gerontologia - produz seus efeitos nas histórias de vida que são produzidas na pesquisa. No projeto associado ao serviço social, as reinterpretações são profundamente infletidas por determinadas concepções sociopolíticas, muitas vezes sintetizadas na ideia da conquista da cidadania ou dos direitos sociais e políticos, enquanto no projeto associado à geriatria, elas são mais marcadas pela releitura dos limites e possibilidades do corpo idoso. Entretanto, o processo social que acionam é basicamente semelhante, podendo ser considerados conjuntamente. 
São também bastante semelhantes os indicadores socioeconômicos acerca da clientela dos dois programas. Embora, por uma série de razões, entre elas a grande flutuação da clientela, não tenha sido possível construir dados estatísticos muito sistemáticos e precisos, alguns dados disponíveis indicam que, em ambos, a clientela constitui-se majoritariamente de mulheres (70 a 80\%), devendo-se, contudo, ressaltar que a participação masculina, embora estatisticamente menor, é muito significativa, implicando uma adesão intensa aos programas. Há, igualmente, diversos indicadores, como a profissão e o rendimento, que apontam para o fato de ser a clientela destes programas, basicamente, oriunda dos segmentos mais estabilizados da classe trabalhadora. ${ }^{20}$

Tais semelhanças autorizam tratar as histórias de vida obtidas como um conjunto único, sem abstrair as diferenças introduzidas por suas ênfases específicas que serão acentuadas quando pertinente. É o que será feito a seguir.

\section{RELENDO O PASSADO COM NOVAS LENTES}

O mais evidente e imediato efeito da inserção nestes programas, talvez o próprio indicador da adesão dos idosos a eles, é a criação de um novo marco em suas riquíssimas histórias de vida, relatado, em todos os casos, sob a fórmula antes e depois da entrada na agência gerontológica. Destaque-se que, sendo as histórias de vida aqui consideradas produzidas no contexto dos próprios programas, muitas vezes no seu espaço físico, este marco responde, também, de certa forma, à projeção que o pesquisado faz das expectativas do pesquisador, visto como identificado à universidade e, por extensão, aos objetivos do próprio programa. Mas, embora esta relativização seja necessária, a frequência e a prontidão com que aparece este corte são indícios suficientes de sua importância simbólica. Um trecho inicial de uma história de vida permitirá expor a forma mais comum pela qual aparece: ${ }^{21}$

Pesquisador - D. Joana, eu queria que a senhora me contasse um pouco da sua história de vida. Para a senhora, como que é a sua vida?

D. Joana - Eu tentei até resumir um pouco pra você a minha vida. Porque antes de conhecer aqui eu era uma pessoa, depois da Sala já sou outra pessoa.

Pesquisador - A senhora era como?

D. Joana - Era assim é... tristonha, depressiva, chorosa, todas essas coisas que uma depressão traz a um ser humano, então eu era assim. Acho que eu vivi a vida toda dessa maneira, por isso eu estou me redescobrindo, né, como disse a doutora ainda há pouco, e descobrindo muitas coisas. A minha vida tá se tornando bem melhor. Eu já não gostava de me vestir, de me arrumar e quando eu era nova sempre fui uma mulher que gostava de me arrumar, de me pintar, de andar bonita; depois foi decaindo, foi decaindo... a idade vai chegando e se não tiver um controle, uma ajuda como a que nós estamos tendo aqui, realmente a gente cai no fundo do poço. Eu cheguei a esse fundo do poço. 
A imagem frequente do fundo do poço cristaliza a descontinuidade necessária para a criação do marco na trajetória de vida que distingue o sujeito anterior do novo sujeito, produzido pela interação na agência gerontológica. O fundo do poço é o espaço simbólico liminar, ${ }^{22}$ condição imprescindível para a separação entre o estado anterior e o novo estado. Como nos ensina Victor Turner, o neófito, nos ritos de passagem, deve assumir a condição de "tábula rasa, uma lousa em branco, na qual se inscreve o conhecimento e a sabedoria do grupo, nos aspectos pertinentes ao novo status" (Turner, I974: I27). Ir ao fundo do poço, portanto, neste caso, é a expressão mais incisiva deste estado liminar, terreno a partir do qual todo o processo posterior poderá ocorrer. Estabelece uma definitiva separação nas características do sujeito, possibilitando sua reformulação ou renovação completa. Trata-se, de fato, como propõem todos os ritos de passagem, de uma morte e um renascimento simbólicos. Neste caso, é preciso morrer como o "antigo velho", passar pelo fundo do poço para renascer como o "novo velho".

O renascimento que caracteriza, em diferentes medidas, a fase atual da vida das pessoas investigadas, tal como aparece em seus relatos, pode ser sintetizado na expressão qualidade de vida, muito divulgada e repetida em todas as atividades dos programas. É parte de uma linguagem comum, exposta continuamente pelos especialistas e apropriada pela clientela. Esta é a expressão mais abrangente e, certamente, a menos definida, utilizada pelos especialistas gerontólogos para designar, ampla e vagamente, os objetivos a serem atingidos. Pressupõe-se que sua condição de possibilidade mais elementar seja a passagem pelo estado liminar, ou seja, a obtenção de qualidade de vida é uma conquista que requer o corte com o estado anterior, estabelecido a partir de um momento zero. Tematizada de inúmeras e variadas formas, a noção de qualidade de vida pode transitar de um conteúdo quase vazio, portando-se como um significante que abriga quaisquer significados, designando genericamente tudo que se quer alcançar, até algumas definições muito precisas, configuradas através de índices mensuráveis de capacidades diversas (cognitivas, físicas, afetivas, sociais, psicológicas etc.). No cotidiano dos programas, conforme apontam as etnografias realizadas, a noção de qualidade de vida funciona como uma legitimação de todo o processo de intervenção. É para obtê-la que é necessário compreender uma espécie de vulgata da biomedicina, da psicanálise, da psicologia e de outras disciplinas acadêmicas cujos receituários, em seu conjunto, terminam por propor uma espécie de normalização biopsicossocial do ser idoso em termos de alguns parâmetros. Pode-se considerá-la, sob tal perspectiva, como a fórmula assumida pelo modelo de pessoa que se objetiva construir. Deve-se ressaltar, entretanto, que a característica principal da noção de qualidade de vida - e, talvez, sua riqueza maior como parte do projeto de intervenção gerontológico - permaneçam sendo esta permanente abertura e labilidade que, se dificultam sua definição precisa, possibilitam a incorporação de significados, por vezes, bastante diversos. 
Como se opera, então, esta reformulação, expressa na ajuda para sair do fundo do poço e alcançar a melhoria da qualidade de vida? Ou melhor, sob que formas aparece nos relatos das histórias de vida dos idosos?

A obtenção de qualidade de vida pressupõe a vivência nos programas, nas suas diversas atividades. A adesão aos programas é, muitas vezes, entendida amplamente como tratamento, termo usado com mais frequência, mas não unicamente, pelos idosos inseridos no programa vinculado ao hospital universitário. Como diz a mesma dona Joana citada acima e, como ela, outros idosos, tudo que eu faço aqui é tratamento. Esta visão sintetiza e ordena a experiência posterior à entrada no programa e completa-se com a referência permanente à ajuda recebida no interior do programa. Mas sinaliza, também, a manutenção da separação entre o nós (clientela) e eles (especialistas, os doutores), detentores do saber acadêmico. Ademais a visão da inserção nos programas como tratamento e ajuda organiza, igualmente, a experiência anterior à entrada no programa, pois pressupõe o reconhecimento de uma situação ou condição de doença ou incapacidade preexistente.

Aí eu fiquei muito baratinada da cabeça, aí minha filha falou: mãe, vai tirar uma consulta com a Estela [psicóloga]. Então eu fui me consultar com ela e ela é que me encaminhou pra geriatria. (Dona Arminda)

Porque eu me sentia deprimida, eu não tinha vontade. Não tinha vontade de sair de casa, não tinha vontade de nada, aí me esforçava muito, sabe? Tinha muita depressão, não tinha vontade de sair de casa, não tinha vontade de conversar com ninguém, não tinha vontade de ver ninguém, nem me arrumava, nada. Mas eu consegui e venci, né? Graças a Deus, eu me sinto agora com mais disposição de vir sozinha porque depressão é muito ruim, é muito difícil você ter alegria, ter prazer, é muito, muito..., mas... felizmente eu venci. (Dona Aurora)

Esta visão resume, assim, o processo como um todo e introduz, nas histórias de vida, a possibilidade de reinterpretação das vivências anteriores. A vida pregressa e a constituição anterior da pessoa são relidas e reavaliadas em termos das ideias e valores condensados no modelo de pessoa - o "novo velho" - que se pretende fazer surgir, desdobrando-se em várias dimensões. Este modelo proposto pelas agências gerontológicas é orientado, como já assinalei, pelo pressuposto de um sujeito biológico universal, naturalizando-se a velhice como acumulação de idade cronológica, ao qual acrescentam-se as diferenças sociais, culturais e psicológicas. Apesar do primado epistemológico da dimensão biológica e universalizante, propõe-se, também, sua apreensão holística - o que justifica a definição do campo da gerontologia como multidisciplinar. A realização do projeto, além disso, demonstrará uma certa inflexão em termos de uma interpretação psicologizante da pessoa.

Uma série de novos termos e expressões, oriundos das discussões acadêmicas, são introduzidos no discurso, pontuando as histórias de vida. A inte- 
ração, muitas vezes cotidiana, de gerontólogos com os idosos, em atividades pedagógicas de diversos formatos apresenta, como resultado mais visível, novas narrativas, em que as verbalizações dos idosos são entremeadas por uma série de concepções oferecidas pelos especialistas. Se a maioria, sem dúvida, provém da medicina e da psicologia, há, também, concepções provenientes de outras áreas, sendo parte da linguagem comum, por exemplo, os termos cidadania e direitos. ${ }^{23}$ Entre estes vários termos, componentes do que poderíamos denominar uma "vulgata gerontológica", necessária para estabelecer um campo de comunicação entre experiências e saberes distintos, destacarei, por sua recorrência e significação, dois de corte mais psicologizante, presentes em quase todas as verbalizações, dos especialistas e dos idosos: depressão e autoestima.

As histórias de vida recolhidas na pesquisa, bem como as diversas outras atividades etnografadas (dramatizações, terapias de grupo, oficinas de texto, corais, oficinas de memória e outras), são diferentes realizações desta "vulgata gerontológica". Colocam em atuação uma série de concepções originárias do discurso acadêmico, isoladas e subtraídas do contexto teórico em que se situam. Muito da reinterpretação das experiências anteriores é obtida pela sua renomeação com os termos e expressões sugeridos pelos especialistas. A noção de depressão é a mais frequentemente incorporada para renomear e, portanto, dar novos significados às experiências vividas, como no exemplo seguinte, de uma idosa, auxiliar de enfermagem:

Trabalhava de manhã, de tarde e de noite, depois das cinco horas, ia atender cliente particular. Quando deparei, meus filhos estavam com aquela vida toda errada, aí pronto. Entrei numa depressão horrorosa. E o marido... depois disso tudo, quis voltar para casa. As crianças já estavam todas casadas. Casada entre aspas, mas todo mundo com família assim...

Do mesmo modo, a falta ou a presença de autoestima opera como eixo semântico na revisitação do passado e na avaliação do sucesso do presente, atribuído à ajuda recebida no programa gerontológico. Há, de certo modo, uma correlação entre o antes, associado à depressão, e o depois, associado à recuperação da autoestima, associações que atualizam, também, a dimensão inatividade (antes/depressão) e atividade (depois/autoestima), um dos eixos do modelo do "novo velho". Todas estas associações são bastante comuns nas narrativas e podem ser resumidamente percebidas neste trecho da história de vida desta outra idosa:

[...] agora eu estou recuperando minha autoestima. Porque eu não tinha autoestima, só fazia tudo o que os outros queriam, engolia sapo, engolia sapo... E aqui nesse trabalho que eles fazem com a gente, com a psicologia, a gente vai aprendendo que a gente tem que se amar a si próprio, primeiro a gente, né, então agora eu já estou aprendendo a dizer não... 
A recuperação da autoestima pressupõe, portanto, o direcionamento do olhar para as emoções, desejos e necessidades do próprio indivíduo, o cuidado de si. Uma dimensão extremamente importante decorrente desta perspectiva é o que Guita Debert denomina "reprivatização da velhice": "Os problemas ligados à velhice passam a ser tratados como um problema de quem não é ativo e não está envolvido em programas de rejuvenescimento e, por isso, se atinge a velhice no isolamento e na doença, é culpa exclusivamente dele" (Debert, I999b: 229)

Vencer a depressão e recuperar a autoestima implica, assim, a adesão a uma perspectiva ativa da pessoa que, em última instância, torna-se responsável por seu próprio bem-estar. Os programas gerontológicos, entendidos como ajuda, apenas possibilitariam ao próprio sujeito o acesso aos instrumentos que lhe permitiriam construir uma velhice bem-sucedida. Sua adesão maior ou menor ao modelo de bem-estar é que determinaria o sucesso maior ou menor do seu empreendimento. Difunde-se, desta forma, junto com o modelo, uma responsabilização da pessoa pelas condições biopsicossociais em que vive. ${ }^{24}$ É neste sentido que Guita Debert afirma que os geriatras teriam "radicalizado a ideia de construção social, acreditando que não há limites para o sucesso do investimento cultural/tecnológico sobre o corpo" (Debert, I999b: 226). Segundo a mesma autora, a relativização proposta pela antropologia seria, neste sentido, "um arrombar de portas abertas" (Debert, I g9gb: 226). Evidentemente, isto não significa que a concepção de velhice não seja naturalizada. De fato, o que parece ocorrer, a meu ver, é uma naturalização de segunda ordem em que, à definição primeira da velhice como fenômeno biológico e idêntico em suas coordenadas básicas para todos os seres humanos, acresce-se a perspectiva de que as diferenças sociais e culturais são exteriores ao fenômeno e, em consequência, mutáveis por uma disposição nova do indivíduo.

Sob tal perspectiva, é a disposição da pessoa para examinar-se e buscar a sua própria "cura" que fica no centro das representações sobre os "novos velhos" produzidos nos programas de intervenção gerontológica. Esta disposição pressupõe, por exemplo, a diferenciação entre os desejos dos outros e os desejos do indivíduo, essencial para operacionalizar a autoestima, como uma das formas principais de realização de uma concepção individualista da construção da pessoa.

Por estes e outros caminhos, a tematização dos valores ligados a uma ideologia individualista (Dumont, I985) fica bastante evidente nas diversas atividades dos programas e consolida-se nas avaliações que compõem as histórias de vida. Talvez devido à predominância de mulheres nos programas, esta tematização, muitas vezes - e mais especialmente no programa ligado à Escola de Serviço Social - apresenta-se como reavaliação das relações de gênero e das relações pais-filhos, provocando uma série de considerações sobre a "submissão feminina", nova chave para a leitura das experiências pregressas da maioria das mulheres. 
E participo de um grupo de psicologia lá... Há pouco tempo foi um assunto bem relevante, porque era geral. A maioria é mulher da minha idade. Eu estou com setenta e dois anos. O assunto era de como fomos criadas. Como era a filosofia daquela época, em que a mulher não tinha opinião. Ela tinha que ajudar o marido, trabalhar, aprender, fazer tudo. Mas não podia dar um ai. Não podia falar, nem dar opinião. O dono da casa, o dono da família eram os homens. As mulheres eram submissas. Aliás, Freud explica isso. Se você ler um livro de Freud, você vai encontrar isso.

A riqueza das histórias de vida recolhidas, que não pode ser totalmente recuperada aqui, deve-se também, em parte, à continuidade do processo de inquirição proposto pela inserção nos programas. Vidas minuciosamente dissecadas nas inúmeras atividades que trabalham com a memória e recuperam experiências passadas, fornecendo novas lentes para sua leitura, cristalizam-se em histórias de vida que também se apresentam, agora, sob a forma permanente do contraste entre as dificuldades e insucessos do passado e a "nova pessoa" mais ativa, participante e segura do presente.

Mas evidenciam-se logo os limites deste processo de reconstrução do passado através de representações coletivas originadas de outra cultura, letrada, de um ethos acadêmico, profundamente marcado por uma ideologia na qual o indivíduo moral é a unidade de análise (Dumont, I985), indivíduo dotado de uma psique que necessita ser esquadrinhada e reconstruída. Numa primeira leitura, são estes princípios simbólicos, oriundos do discurso acadêmico, que parecem ser incorporados como organizadores das narrativas das histórias de vida que os idosos constroem para o pesquisador, evidenciados na ampla utilização dos termos e expressões referidas bem como de ícones do discurso psicologizado (por exemplo, Freud explica isso). Contudo, opera-se, muito claramente, uma segunda reinterpretação: a das categorias analíticas oferecidas pelos especialistas que, então, incorporam-se às referências culturais diversas trazidas pelos idosos.

Esta segunda reinterpretação - a que os idosos fazem das categorias que recebem para reler suas vidas - denuncia, também, os limites do relacionamento entre culturas que operam com princípios simbólicos distintos. Partilhando, por sua origem social, uma configuração cultural de referência dos trabalhadores, a maioria dos idosos que adere a estes programas partilha também uma concepção da pessoa bastante distinta daquela que informa as especialidades acadêmicas que orientam a intervenção. Construídos como seres sociais plenos através das relações significativas de que partilham, particularmente as relações familiares e de parentesco (Duarte, I986; Guedes, I997), reinterpretam as categorias individualistas no contexto destas relações. Assim é que a depressão dificilmente é compreendida, nestas histórias de vida, como resultante de processos inconscientes de construção do indivíduo, mas, em quase todos os casos, como resultado de relações familiares e de parentesco problemáticas. Trata-se de um processo específico de construção da pessoa, em que a doença, relida 
como procurei demonstrar, como depressão, resulta da avaliação do estado e das condições destas relações. Assim, dona Lúcia, por exemplo, não pode deixar de avaliar-se a partir da avaliação que faz do "insucesso" de seus filhos:

Mas eu, pra mim, não sou uma mulher realizada. Não vi filho nenhum formado, não vi filho nenhum casado direitinho. Quer dizer, isso me deixou muito doente, mas hoje, graças a Deus, já saiu isso tudo da minha cabeça. Hoje eu reconheço que a vida é assim mesmo, não choro mais, chorei muito, muito, muito...

E dona Aurora atribui sua depressão às perdas familiares:

Ah... eu fiquei deprimida, não foi, só pela aposentadoria, acho que muito problema na família que aconteceu, muitas coisas que aconteceram que eu fiquei... carregando, carregando, carregando..., foi acumulando coisas: como a morte, minha irmã mais nova..., depois de sete meses, que a minha irmã morreu, morreu meu cunhado, a minha irmã que mora em Belém adoeceu, teve uma doença muito grave, veio pra cá, pra vir pra Niterói, pra eu tomar conta dela, eu cuidava dela, trabalhava... e esse tempo todo, eu estava assim...segurando, segurando...

Além disso, outras categorias interpretativas como a do nervoso, com amplos e importantes significados na cultura de classe trabalhadora (ver Duarte, I986), convivem nas histórias de vida com as concepções fornecidas pelos especialistas dos programas e disputam a capacidade de organizar o discurso. Dona Magnólia, por exemplo, nos fala de sua vida passada tendo como centro o nervoso de seu marido:

Um homem sempre nervoso, um homem que estava sempre de mal com a vida. Eu não tinha do meu lado um jovem alegre, como eu achei que ia ter, e eu era bem mais moça do que ele. Eu levei uma vida muito dura. Eu tinha que segurar o nervoso do meu marido e os meus filhos, que eu dava toda a atenção pra eles. Então, o meu refúgio maior foram eles e a educação que a gente recebia, que o casamento era uma coisa muito séria.

Portanto, a forma como as concepções oriundas do discurso acadêmico letrado são incorporadas nas histórias de vida dos idosos em projetos gerontológicos, sugerem que elas são destacadas dos contextos simbólicos de que provêm, sofrendo um processo de ressemantização no interior das referências culturais básicas de seus receptores. São, neste sentido, reinterpretadas. Se, por um lado, fornecem novas lentes para a leitura das experiências vividas, por outro não resistem à força de outros mecanismos interpretativos já consolidados e devem conviver com categorias plenas de significado que atuam conjuntamente na leitura deste passado. As histórias de vida recolhidas neste projeto de pesquisa apresentam, simultaneamente, as marcas de seu diálogo com outra cultura e a resistência das interpretações cristalizadas através de outras concepções, estranhas à ideologia individualista que preside tais programas, configurando-se uma espécie de embate simbólico entre concepções individualistas e relacionais da pessoa (ver, também, Ropa \& Duarte, I985). A “versão 
de si" apresentada aos pesquisadores neste contexto intercultural apresenta todas as marcas das tensões destes embates nas avaliações dos eventos que apresenta e destaca.

As agências gerontológicas, como outras instituições intermediárias na sociedade moderna, buscam divulgar e disponibilizar concepções e saberes elaborados nos meios acadêmicos, dotando-se de uma evidente dimensão pedagógica. Na interação com pessoas construídas segundo outros princípios simbólicos, profundamente sedimentados, cuja identidade é elaborada no entrecruzamento de inúmeras relações familiares, de parentesco, de amizade, de vizinhança, acrescenta uma dimensão que é vivida como nova, propondo uma inquirição de emoções e sentimentos individuais, provocando uma atenção nova aos sintomas do corpo, fornecendo concepções e instrumentais que legitimam leituras distintas das inserções sociais e políticas até então disponíveis para estas pessoas.

A reconstrução etnográfica aqui empreendida e, no seu contexto, em especial as histórias de vida obtidas, indicam a criação de um terreno mais fluido e flexível, em que se a pessoa construída em termos decisivamente relacionais não se transforma no indivíduo moderno, delimitado e dotado de uma psique determinante, dissecador de si mesmo, ele se torna o ser resultante de uma nova subjetivação, construindo-se tanto quanto é construído. Este processo também nos lembra que, como diz Marshall Sahlins, as categorias estão sempre em risco na ação. ${ }^{25}$ Neste caso, estão em risco as categorias provenientes do discurso letrado e as categorias provenientes da cultura de classe trabalhadora, possibilitando a emergência de um espaço simbólico novo e imprevisível. Ao ressemantizar as categorias oriundas do discurso letrado produz-se um território novo em que o indivíduo relacional redefine suas relações sem deixar de ser definido por elas. Estes idosos estão, de certa forma, reinventando uma cultura. 
Simoni Lahud Guedes é Doutora em Antropologia Social pelo Museu Nacional/UFRJ. É professora do Departamento de Antropologia da Universidade Federal Fluminense (UFF), onde foi coordenadora do Programa de Pós-Graduação em Antropologia. Suas pesquisas abordam temas como trabalhadores urbanos, futebol brasileiro, categorias etárias. Coordenou a Comissão de Ensino e Ofício da Associação Brasileira de Antropologia (ABA), e é membro do Instituto Nacional de Ciência e Tecnologia-Instituto de Estudos Comparados em Administração Institucional de Conflitos (INCT-InEAC) e coordenadora de convênios CAPES-SPU (Argentina). 


\section{NOTAS}

* Este artigo desenvolve questões apresentadas inicialmente como comunicação na XX Reunião da Sociedade Brasileira de Pesquisa Histórica (SBPH), realizada no Rio de Janeiro, em 2000, e publicada nos Anais da XX Reunião da SBPH, Curitiba, 200I , p. 37-43, sob o título "Experiência e memória: os limites da reconstrução do passado nas histórias de vida de idosos em projetos de gerontologia".

I A imposição de coerência e sentido linear na construção de biografias foi analisada por Bourdieu (I996) e denominada como "ilusão biográfica". Foi também apresentado e discutido no III Congresso Latinoamericano de Antropologia (ALA), realizado de 4 a ro de novembro de 2012 em Santiago, Chile.

2 A presença do indivíduo como valor, na sociedade moderna pós-Iluminismo, é extensamente elaborada na obra de Louis Dumont (ver, por exemplo, I985).

3 Na verdade, a entrevista é apenas uma das técnicas utilizadas para a construção das histórias de vida. Documentos, fotografias e diversos outros tipos de dados podem e devem ser utilizados para tal fim.

4 O material empírico utilizado neste artigo foi produzido, em diferentes momentos e contextos, por mim e pelos bolsistas de Iniciação Científica Sandra de Araújo Gonçalves, Felipe Domingues dos Santos e Rosângela dos Santos Bauer, em projetos que coordeno apoiados pelo CNPq. Nos dois últimos anos venho desenvolvendo o projeto denominado "Experiência e memória: a transmissão de saberes entre trabalhadores urbanos".

5 "A espetacularização do mundo é, primeiramente, o fato da proliferação de imagens que se impõe cada vez mais aos cidadãos espectadores. O 'conhecimento' do Planeta, que hoje quase qualquer um de seus habitantes pode ter, passa evidentemente pelas imagens dele que a televisão, principalmente, lhe mostra. Mas a imagem não vem isolada: a história do dia-a-dia é apresentada pelo conjunto da mídia como que se desenvolvendo em um certo número de cenas". (Augé, I997: 104).

6 Stuart Hall (I999: 92), por exemplo, anota esta recriação da diferença como uma característica da contemporaneidade: 
“[...] existem também fortes tentativas para se reconstruírem identidades purificadas, para se restaurar a coesão, o 'fechamento' e a Tradição, frente ao hibridismo e à diversidade."

7 Para uma análise aguçada dos principais teóricos que tratam dos processos de subjetivação na pós-modernidade, ver Fridman (2000).

8 "O poder deve ser analisado como algo que circula, como algo que só funciona em cadeia. Nunca está localizado aqui ou ali, nunca está nas mãos de alguns, nunca é apropriado como uma riqueza ou um bem. O poder funciona e se exerce em rede. Nas suas malhas os indivíduos não só circulam, mas estão sempre em posição de exercer este poder e de sofrer sua ação; nunca são o alvo inerte ou consentido do poder, são sempre centros de transmissão. Em outros termos, o poder não se aplica aos indivíduos, passa por eles". (Foucault, I979, p. I83).

9 Para o conceito de sedimentação de significados, ver Berger \& Luckman (1973).

Io Venho discutindo este processo em diversas investigações, tomando como material empírico as histórias de vida de trabalhadores urbanos no Grande Rio, sustentadas e cruzadas com material proveniente de outras técnicas. Ver, entre outros artigos, Guedes (I998; I999).

I I Delma Pessanha Neves vem desenvolvendo extenso trabalho de investigação sobre o alcoolismo, num projeto integrado em que uma das pesquisas, em andamento, é a de Angela Maria Garcia sobre os Alcoólicos Anônimos. Temos nos beneficiado dos debates e comparações entre tais agências no interior do Grupo de Pesquisa Transmissão do Patrimônio Cultural, no qual se desenvolvem também nossos projetos.

I 2 As palavras destacadas em itálico são parte das verbalizações registradas nas etnografias, quer dos especialistas gerontólogos quer dos idosos.

I3 Examinei, mais atentamente, este modelo da "nova velhice" professado pelas agências gerontológicas em Guedes (2000).

I4 Para a divulgação da perspectiva associada à noção de terceira idade nos jornais cariocas nos últimos anos, ver Gonçalves (2000). 
I5 Ver Bauer (2000), Gonçalves (2000) e Santos (2000) para os resultados deste trabalho.

I6 São aqui considerados fundamentais os postulados estabelecidos pela antropologia social e pela história social (ver, por exemplo, os "clássicos" de Van Gennep, i978, e Ariés, I978), que demonstram a origem cultural dos marcos etários e sua consequente naturalização nas visões de mundo.

I7 Mais adiante será discutida a forma específica pela qual tais diferenças são inseridas no modelo, sem alterar substantivamente a concepção universalizante e biologizante do fenômeno da velhice.

I8 No artigo referido anteriormente (Guedes, 2000), procurei demonstrar algumas das dificuldades decorrentes da inserção de múltiplas tradições disciplinares na gerontologia e, ainda, a dominância dos princípios epistemológicos universalizantes da geriatria nas intervenções da gerontologia.

I9 Ver Santos (2000), em trabalho que destaca, particularmente, um viés feminista observável em algumas atividades do programa referido..

20 Alguns dados estatísticos mais consistentes sobre o programa associado ao Hospital Universitário Antonio Pedro podem ser obtidos em Vidon (I998).

2 I Os nomes dos entrevistados, como é usual nos trabalhos antropológicos, são fictícios, expediente que visa proteger as identidades das pessoas pesquisadas.

22 Ver, para a noção de liminaridade como associada aos rituais de passagem, Van Gennep (I978) e Turner (I974).

23 Neste caso, mais visivelmente no segundo programa, ligado à Escola de Serviço Social. Mas tais concepções não estão, de modo algum, ausentes do programa ligado ao hospital universitário.

24 Este processo não é, evidentemente, exclusivo da gerontologia. Trata-se, como procurarei registrar abaixo, de uma das dimensões da valorização do indivíduo na cultura moderna.

25 "As pessoas colocam, na ação, seus conceitos e categorias em relações ostensivas com o mundo. Esses usos referenciais põem em jogo outras determinações dos signos, além de seus significados recebidos, ou seja, o mundo real e as pessoas envolvidas." (Sahlins, I990: I85). 


\section{REFERÊNCIAS BIBLIOGRÁFICAS}

Ariés, Philippe. (1978). História social da criança e da família. Rio de Janeiro: Zahar.

Augé, Marc. (I997). Por uma antropologia dos mundos contemporâneos. Rio de Janeiro: Bertrand Brasil.

Bauer, Rosangela dos Santos. (2000). A construção do corpo num projeto gerontológico. Monografia de Bacharelado em Ciências Sociais, Universidade Federal Fluminense.

Behar, Ruth. (1995). Rage and redemption: reading the life story of a Mexican marketing woman. In: Tedlock, Dennis \& Mannheim, Bruce (orgs.). The dialogic emergence of culture. Urbana e Chicago: The University of Illinois Press, p. I48-I78. Berger, Peter \& Luckmann, Thomas. (1997). Modernidad, pluralismo y crisis de sentido. La orientación del hombre moderno. Barcelona/Buenos Aires/México: Paidós.

Berger, Peter \& Luckmann, Thomas. (I973). A construção social da realidade. Tratado de sociologia do conhecimento. Petrópolis: Vozes.

Bourdieu, Pierre. (I996). A ilusão biográfica. In: Ferreira, Marieta M. \& Amado, Janaína (orgs.). Usos e abusos da história oral. Rio de Janeiro: Ed. FGV, p. I83-I92.

Debert, Guita G. (I999a). A construção e a reconstrução da velhice: família, classe social e etnicidade. In: Neri, Anita Liberalesso \& Debert, Guita Grin (orgs.). Velhice e sociedade. Campinas, SP: Papirus.

Debert, Guita G. (I 999b). A reinvenção da velhice. Socialização e processos de reprivatização do envelhecimento. São Paulo: Edusp/ Fapesp.

Debert, Guita G. (I986). Problemas relativos à utilização da história de vida e história oral. In: Cardoso, Ruth (org.). A aventura antropológica. Teoria e pesquisa. Rio de Janeiro: Paz e Terra, p. I4I-I56.

Duarte, Luiz Fernando. (I986). Da vida nervosa nas classes trabalhadoras urbanas. Rio de Janeiro: Zahar.

Dumont, Louis. (1985). O individualismo: uma perspectiva antropológica da ideologia moderna. São Paulo: Rocco.

Foucault, Michel. (I995). O sujeito e o poder. In: Rabinow, Paul \& Dreyfus, Hubert (orgs.) Michel Foucault: uma trajetória 
filosófica. Para além do estruturalismo e da hermenêutica. Rio de Janeiro: Forense Universitária.

Foucault, Michel (I979). Microfísica do poder. Rio de Janeiro: Graal: 1979 .

Foucault, Michel. (1977). Vigiar e punir. História da violência nas prisões. Petrópolis: Vozes.

Fridman, Luis Carlos. (2000). Vertigens pós-modernas. Configurações institucionais contemporâneas. Rio de Janeiro: Relume-Dumará.

Gonçalves, Sandra de Araújo. (2000). Imagens da velhice e do envelhecimento em jornais cariocas. Monografia de Bacharelado em Ciências Sociais, Universidade Federal Fluminense. Guedes, Simoni Lahud. (200I). Experiência e memória: os limites da reconstrução do passado nas histórias de vida de idosos em projetos de gerontologia. Anais da XX Reunião da SBPH, Curitiba, p. 37-43.

Guedes, Simoni Lahud. (2000). A concepção sobre a família na geriatria e na gerontologia brasileiras: ecos dos dilemas da multidisciplinaridade. Revista Brasileira de Ciências Sociais, I5/43, junho, p. 69-82.

Guedes, Simoni Lahud. (I999). História de vida e história local: a construção social da memória. Anais da XVIII Reunião SBPH, Curitiba, p. 99-102.

Guedes, Simoni Lahud. (I998). A pedagogia dos casos: experiência e memória na vida dos trabalhadores urbanos. In: Oral history: challenges for the $2 \mathrm{I}^{\text {st }}$ century. Xth International Oral History Conference: Proceedings. Rio de Janeiro: Ed. FGV, vol. I, p. 52-59.

Guedes, Simoni Lahud. (I997). Jogo de corpo: um estudo de construção social de trabalhadores. Niterói: Eduff.

Hall, Stuart. (1997). A identidade cultural na pós-modernidade. Rio de Janeiro: DP\&A Editora.

Ropa, Daniela \& Duarte, Luiz Fernando. (1985). Considerações teóricas sobre o "atendimento psicológico" às classes trabalhadoras. In: Figueira, Sérvulo (org.), Cultura da psicanálise. São Paulo: Brasiliense, p. I78-20I.

Sahlins, Marshall. (I990). Ilhas de história. Rio de Janeiro: Zahar. 
Santos, Felipe Domingues. (2000). As releituras das histórias de vida e sua transformação em experiêncis coletivas. Monografia de Bacharelado em Ciências Sociais, Universidade Federal Fluminense.

Turner, Victor. (I974). O processo ritual: estrutura e anti-estrutura. Petrópolis: Vozes.

Van Gennep, Arnold. (1977). Os ritos de passagem. Petrópolis: Vozes.

Velho, Gilberto \& Kuschnir, Karina. (I996). Mediação e metamorfose. Mana - Estudos de Antropologia Social, 2/ I, abril, p. 97-108.

Vidon, Maria Acácia. (I998). Sala de espera e o idoso na proposta de educação e saúde. Monografia apresentada ao Curso de Especialização em Geriatria e Gerontologia, Universidade Federal Fluminense. 
Palavras-chave

Idosos; Identidade;

Histórias de vida;

Projetos gerontológicos;

Sociedades complexas.

Keywords

Seniors; Identity;

Life stories;

Gerontological projects;

Complex societies.
VIDAS REVISITADAS:

\section{A RECONSTRUÇÃO DO PASSADO DE IDOSOS EM PROGRAMAS GERONTOLÓGICOS}

\section{Resumo}

Examino, neste artigo, o processo de reconstrução do passado de idosos engajados em projetos gerontológicos, utilizando material empírico produzido em pesquisas sob minha coordenação. Seguindo a orientação de Ruth Behar, considero que cada narrativa chamada de "história de vida" constitui-se na produção de um texto que é uma versão do self construída por um sujeito. Neste sentido, o artigo tem dois objetivos: o primeiro, de ordem teórico-metodológica, visa acentuar a dimensão interpretativa e situada das narrativas estudadas, verificando como algumas categorias interpretativas ordenam a produção das histórias de vida em agências gerontológicas; o segundo é contribuir para uma discussão mais ampla sobre as formas de relacionamento entre culturas diversas em sociedades complexas.

\section{LIVES REVISITED:}

\section{THE RECONSTRUCTION OF THE SENIORS' PAST} IN GERONTOLOGICAL PROGRAMS

\section{Abstract}

The article addresses the reconstruction of the past of seniors engaged in gerontological projects. It emphasizes that each of the narratives we call "life story" consists in producing a text that "is, in fact, not the person, but a version of the self constructed by a subject", as Ruth Behar put it. That said, the article has two objectives: the first is a theoretical-methodological one, and accentuates the interpretative and situated dimension of these narratives, exploring how some interpretive categories organize the production of life histories in geriatric agencies; the second is to contribute to a broader debate about the forms of relationships between different cultures in complex societies. 